\section{Bridging an old rivalry}

\section{Tokyo}

JAPAN's two space agencies, the National Space Development Agency (NASDA) and the Institute of Space and Astronautical Science, may join forces for the first time ever to develop a large solid-fuel rocket, if a proposal put forward by NASDA this week to the Space Activities Commission is accepted. The proposal indicates a warming in relations between the two former rival space agencies that may strengthen Japan's space industry and space science programme.

Japan is the only country in the world that has two independent governmentrun space agencies each with its own launch sites and rockets. The smaller but older Institute of Space and Astronautical Science began its ventures into space in the mid-1950s with the launch of a small solid-fuel rocket called Pencil. By last year, the institute, working on a shoestring budget from the Ministry of Education, Science and Culture, managed to launch Japan's first probe to the Moon with one of its domestically developed solid-fuel rockets (see Nature 343, 403; 1990). And the little institute has had a string of successes in its pursuit of the scientific study of space over the past few decades.

NASDA, which was established by the Science and Technology Agency in the late 1960 s and now has nearly ten times the annual budget of its academic counterpart pursued an entirely different path. It imported expensive US rocket technology and used it to launch mainly applications satellites, such as weather and communications satellites. The agency also launches some Earth observation satellites for scientific purposes.

Over the past decade, NASDA has been reducing its dependence on US rocket technology by developing Japanese-made liquid-fuel engines, such as that in the second stage of its current H-I rocket. By 1993 the agency hopes to launch its next-generation $\mathrm{H}$-II rocket, which will be made entirely made in Japan.

It is NASDA's gradual switch to domestically developed rocket technology that has created the opportunity for the two agencies to develop a rocket jointly. In the proposal submitted this week, NASDA calls for the solid-fuel booster rockets of the H-II to be combined with the second stage of the academic space institute's M-3SII, the rocket that sent a probe to the Moon last year.

The hybrid rocket could be used to launch medium-sized, one-ton satellites into low Earth-orbit at very low cost. NASDA is also keen to use the new rocket for supersonic, upper-atmosphere test flights of the agency's proposed unmanned space shuttle HOPE, which will service the Japanese module of the planned US Space Station (see Nature 351, 680; 1991).

Jun Nishimura, director general of the smaller agency, says the NASDA proposal is a "very interesting possibility". The solid-fuel boosters for the H-II were developed by Nissan motor company using the institute's technology (Nissan also makes the institute's rockets). And so combining the two would be quite logical, says Nishimura.

But the institute jealously guards its independence and is eyeing the NASDA proposal warily. Relations between the two space agencies were strained for many years because, in an unusual political deal in the late 1960 s, the Ministry of Education, Science and Culture and the Science and Technology Agency agreed to limit the tail diameter of the institute's rockets to a maximum of 1.41 metres so that the institute did not compete with the newly formed NASDA.

The size limit was recently lifted, opening the way for the institute to begin developing a much larger rocket, the $\mathrm{M}-\mathrm{V}$, which will be able to lift 2-ton satellites into low Earth orbit.

Many Western observers comment on the seeming inefficiency of having two space agencies. But the institute's scientists argue that the division of roles has enabled them to run a very cost-efficient and low-budget space science programme unmatched by any other space agency in the world. They have no intention of merging with the larger agency, they say.

The sharing of rocket technology, however, would expand the choice of launch vehicles and allow greater flexibility in the size of payloads, and so the idea is being seriously considered by the institute, although a decision will take many months. No matter what the outcome, NASDA's proposal does seem to herald a new era of cooperation between the two agencies.

David Swinbanks

\title{
An urgent search for power
}

\section{Tokyo}

TOKYO Electric Power Company, the world's largest private electric utility company, last week turned on all 13 of its nuclear power generators to try to cope with a surge in demand for electricity during Japan's steaming hot summer. The company will also rekindle two fossil-fuel thermoelectric power plants to meet a demand that is expected to reach the brink of the power company's capacity.

The summer energy shortage is drawing attention here to critical problems that Japan faces in expanding its energy sources, nuclear power in particular.

In recent years, Japan's energy consumption has defied government predictions and grown at about five per cent a year, twice the projected rate. Much of the increased demand is coming from private households that have recently bought energy-guzzling air conditioners.

Last summer, Tokyo Electric came within a few per cent of its maximum electric power generating capacity during peak demand periods. The company was able to buy extra capacity from neighbouring power companies to maintain an adequate safety margin, but the option to buy surplus electricity is much more limited this year at a time when demand is expected to be even greater.

In February, the Tokyo power company's largest neighbour, the Kansai Electric Power Company, suffered a major setback: one of its oldest nuclear power reactors was shut down during an emergency (see Nature 349, 557; 1991). The
$500,000-\mathrm{kW}$ Mihama reactor is not expected to come back on line for at least another three years. And shortly after the Mihama accident, the Kansai company's Takahama No. 2 reactor had to be also closed down. As a result, the company is also struggling to meet energy demands and has no surplus power to sell to its energy-hungry neighbour.

Both companies are looking to fossilfuel plants to cope with the energy crisis. Tokyo Electric will reactivate two thermoelectric power generators in Chiba prefecture next to Tokyo to help cope with anticipated demand this summer. Kansai Electric is planning to build two large thermal power plants fuelled with liquefied natural gas and another powered by coal by the end of this century.

The move back to fossil fuel has focused attention on the problems of finding new sites for nuclear power plants. Japan's Ministry of International Trade and Industry has called for 40 new nuclear plants to be built by 2010 . Eleven plants are under construction, but there is growing local opposition to nuclear power, and the government and industry have been unable to allocate any new sites in recent years, despite huge financial incentives for local governments to accept nuclear power plants.

Switching back to fossil fuel is not a viable alternative in the long run because Japan has pledged to hold its output of carbon dioxide emissions to the 1990 level after the year 2000 .

David Swinbanks 